\title{
The Impact of Cross-Border Cooperation and Brand Co-Branding on Product Sales and Customer Loyalty
}

\begin{abstract}
Jiahao $\mathrm{Xu}^{1, \mathrm{a}}$
Xi'an Tieyi high school, Xi'an, Shaanxi, 710054, China

Corresponding author's e-mail: angela@cas-harbour.org

ABSTRACT

This article studies how brand cross-border cooperation affects customer loyalty and customer numbers. The model of cross-border cooperation between the two brands will be used in this article. This article adopts a qualitative method and selects multiple peer articles for theoretical basis and analysis. Meanwhile, sales data and keywords searched on the sales platform are collected for verification. Because brand cross-border cooperation has the advantages of sharing resource, saving capital, increasing brand topical heat, and accumulating customer loyalty, it can be concluded that cooperative marketing will be beneficial to brand marketing. But at the same time, there are some potential risks in brand cooperation. For example, meaningless cooperation will lead to customer loss. Therefore, brands should try to avoid these problems when conducting cross-border marketing with partners.
\end{abstract}

Keywords: Brand loyalty, Customer mobility, Collaboration, Co-Marketing, Brand spirit

\section{INTRODUCTION}

As market competition intensifies, the mutual penetration of industries and brands is inevitably emerging and becoming trendy. A single industry is no longer satisfied with producing a single product, but tends to diversify products to better reflect the spirit of the industry.

Brand cross-border cooperation through the cooperation with other brands, IP, celebrities to generate new products, with the help of both parties to enhance the brand or product commercial value. Co-branded models are the most consistent with "products as marketing" methods. They are not only product-level innovations, but also have the value of topic communication and brand building. Because of the extensive social and communication attributes of brand cooperative marketing, this approach presents a blowout growth. The marketing based on customers' demand can make it easier and faster for customers to consume. This article mainly investigates increasing the brand's customer base through "cooperative marketing" to achieve the purpose of "mutual drainage".

This article will focus on how the behavior of cooperative marketing between two different industries or two different brands will affect their own number of customers or groups of loyal customers. This study looks at the interaction of user loyalty between different brands or industries, and finds out how this interaction will affect the brand's customer base.

The purposes of this article is to make recommendations for the future marketing methods of the branding, and some predecessors did not consider the brand spirit and customer loyalty when researching related aspects, this article also complements the previous research in this issue.

\section{LITERATURE REVIEW}

The research similar to this research is as follows: Bai Yanhui and others studied some clothing cooperation marketing cases in 2019[1], summarized the problems in brand cooperation, and proposed that although brand cobranding is very popular, if the information does not arouse consumer interest, the co-branding is still not well known. Therefore, when cooperating with brands, they should select brands that can enhance their brand image through the attachment effect, or adopt unusual cooperation methods such as cross-border cooperation in the industry. At the same time, if the brand's cooperation lacks sincerity, that is, the work lacks design sense, it will not be loved by consumers, because this does not show the brand's respect for consumers. Bai, etc. (2019) also uses the literature review method to collect relevant data, and explores the motivation of brand cooperation: improving brand awareness and influence, achieving value added, promoting consumption, and reducing brand operating consumption[2] Bai, etc. (2019) believes that brands need to be continuously exposed, so co-branding can provide such opportunities, which can bring good advertising effects to both brands. And according to consumer psychology, the fundamental purpose of clothing brand joint name is to please consumers, because this marketing method is more likely to attract consumers' attention, and it can make consumers understand both brands at the same time. This has a collateral effect because one party is interested in the other. Consumers will also be fortunate to purchase these limited-edition branded joint-name products, and produce a sense of satisfaction that doubles the effect of purchasing one product, providing consumers with a rich psychological experience. Finally, according to the investigation and analysis of Bai, etc. 
(2019), clothing brands should reasonably choose cooperative brands when co-branded marketing, pay attention to the exposure of co-branded time, and value the quality and design of co-branded products, which will help improve the brand co-branding effect and brand building. $\mathrm{Xu}$ Naizhen and others proposed in 2013 the combination of cross-border marketing and brand communication, which can realize resource integration and stimulate users' love for multiple brands, and ultimately achieve a win-win situation for the brand[3]. This can be specifically understood in the article as a fusion and extension of some elements that were originally not related, based on the commonalities and connections between consumers in different industries, different products, and different preferences. Life attitude, aesthetic taste or values, in order to win the favor of target consumers, so as to maximize the market and profit of crossborder joint ventures. $\mathrm{Xu}$, etc. (2013) proposes that this is an emerging marketing model, representing a fusion of a cutting-edge lifestyle and aesthetic approach. Through analysis and summary, the article finally proposes that the core of cross-border marketing is its essence, which is to solve the existing problems in the new marketing environment through innovation and achieve a win-win situation for both parties. The combination of cross-border marketing and brand communication can stimulate customers' love for the brand, boost the impact of activities, and improve customer experience perception, so as to obtain better communication effects.

\section{METHODOLOGY}

The author use a way of consulting the literature. During the research process, the author searched more than 40 articles about brand cooperation, brand image, and user loyalty on the Internet, and finally downloaded 16 and carefully studied 6 of them. While studying, the author extended and classified the theories and ideas mentioned in the article, and summarized them in the article.

The author used a method of analyzing data to improve this article. Because some cross-border cooperation brands have not yet been listed, the brand's annual report is not available. Therefore, the author collected data from the sales platform for analysis and adopted some sales platform reports on brand cooperation marketing.

This article also uses a qualitative analysis research method to search for relevant information through Internet channels and books and periodicals, and also discusses with others and constantly reflects on notes and various text pictures to obtain the required information. After searching these materials, the author integrated and analyzed them, and at the same time reflected the summarized information to the reader.

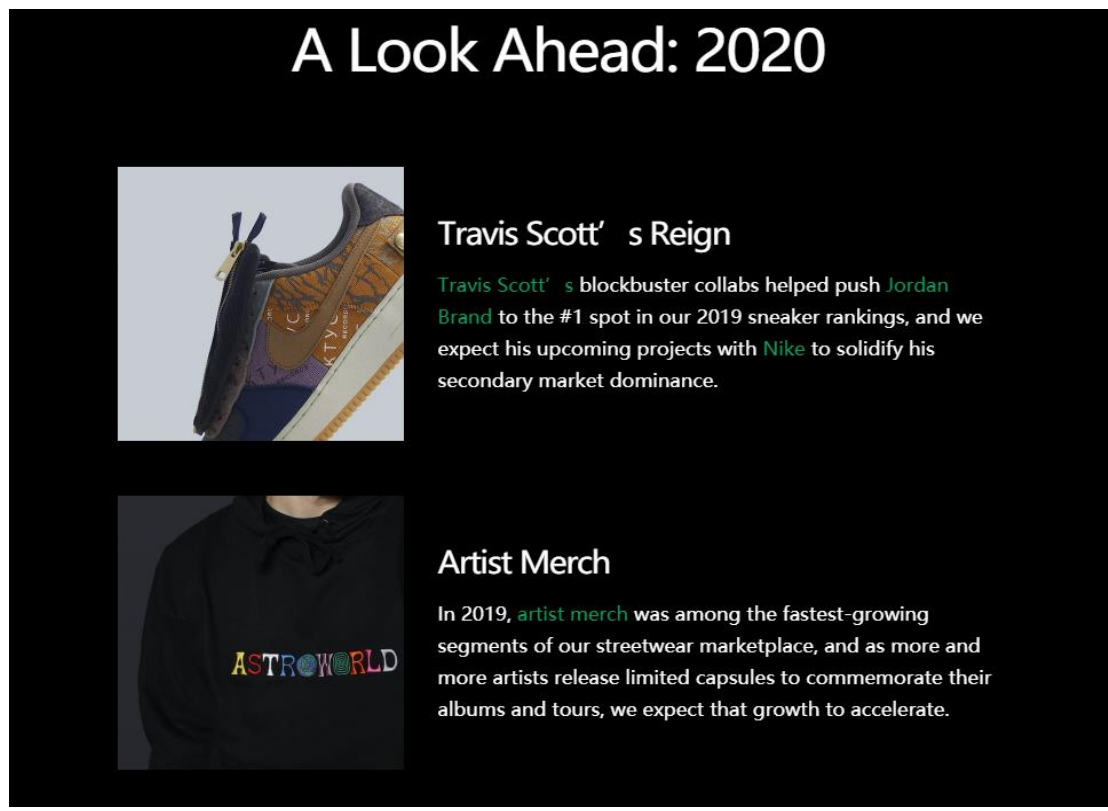

Fig.1 Keyword popularity on StockX

\section{INTRODUCTION AND ANALYSIS OF COOPERATION MODELS}

The US sneaker trading platform StockX released the 2019 State of Resale Report[5], which details the second-hand transactions of the platform in sports shoes, tide brands and luxury goods in the past year, and reveals the latest trends in the second-hand market and made predictions for future development. In addition, several major keywords for 2020 were shown, namely artist collaboration and star collaboration. It can be seen that the enthusiasm for crossborder cooperation is high, because cross-border cooperation has many benefits. However, there are also potential risks that some brands do not realize. 
Co-branded brands are brand cross-border collaborations that enable a marketing approach to generate new products through cooperation with other brands, IPs, and celebrities. Brands often use this method to leverage the influence of both parties to enhance the brand or product commercial value. Co-branding is not only product-level innovation, but also the value of topic communication and brand building. Co-branding or cross-border cooperation of brands mentioned in this article, including but not limited to the methods given below.

\subsection{Cooperation between brands and celebrities}

Celebrities are divided into four categories: one is a star, the other is a well-known designer and artist, the third is a virtual character, and the fourth is an industry blogger.

This method is more common, sports brands like to find sports stars, fashion brands look for traffic stars, foreign brands look for well-known designers and artists, and so on. There are several ways to cooperate, some are printed with celebrities' images, some are designed by celebrities, and some are combined with celebrities to form gift boxes for sale.

The advantage of this marketing model is that the cobranded object has a large number of fans, and the brand can use its fans to achieve sales growth; the topicality of the celebrity itself easily triggers the spread of social media; celebrities can also rely on this cooperation to draw closer Distance from fans.

However, the disadvantage is that this kind of cooperation may lead to the failure of marketing of cooperative products due to the bad personality of the celebrities or the outbreak of scandals.

\subsection{Cooperation between brands and IPS}

Generally, IP includes movie IP (Marvel), anime IP (One Piece, Pikachu, Piggy Page), cultural IP (Forbidden City, British Museum), game IP (Glory of Kings, League of Legends), and Internet IP.

The advantages of this cooperative marketing model are: Brands and IP co-marketing can make IP more affinity, rather than a fancy image; if IP's peripheral products are done well, it can also increase its popularity; stars have scandals, scandals uncertainty and human collapse, etc., these issues will help build the brand image, IP perfectly circumvents these issues.

The disadvantage of this method of cooperation is that some manufacturers will misappropriate cooperation ideas to produce inferior copycat products and cause the cooperation reputation to drop.

\subsection{Cooperation between brands}

This is the most popular cooperative marketing method that has emerged in recent years, because this cross-border cooperation method is convenient and attracts customers, and it adopts a method that integrates two brand design concepts and characteristics.

The advantages of this cooperative marketing model are as follows: it can enjoy the customer resources of both brands at the same time, it can better increase the product premium, and it can establish a brand diversified image.

The disadvantage of this method of cooperation is that when you attract fans of another brand, you will also be hated by customers who do not like that brand.

\section{FINDINGS}

\subsection{Advantages}

The essence of commercial trade is nothing more than the exchange of goods. What drives customers to exchange is how much they know about the product. The customer's awareness of the product must be based on the product's exposure, which is the significance of cross-border marketing. Because whether it is the cooperation between brands and celebrities, or with IP, or cross-border cooperation between brands, it will cause discussion. This creates propagation and flow pulses, and the emergence of topics is a good opportunity to increase exposure. Let potential customers quickly generate brand awareness and achieve the effect of $1+1>2$. Therefore, the brand can attract enough customer traffic (which will form a loyal customer group in the future) and obtain sufficient profits. Because cross-border cooperation products are jointly designed and produced by two parties' brands or industries, so one product has two characteristics. That will cause customers to have a psychological state when they buy one item and get two products. In this case, the product will have a premium space, because the customer sees that product as two items instead of one item, that is, the customer thinks that the combination of the two brands should have a higher price. In addition, cross-border cooperation can cover the product audiences of both parties to achieve a product complementary effect, so that it can reach more potential consumer groups to increase the audience of its own brand, which is a win-win situation for both parties. Take Bulgari Hotel as an example, it is a typical cross-border cooperation. Through the cooperation of the hotel industry and the jewelry fashion industry, customers from both industries can be obtained at the same time.

The hunger marketing of cross-border cooperation has led to the extension of non-product functions. The current brand cooperation marketing is generally limited edition. During the entire sale process, the brand will carry out a lot of publicity in the early stage to enhance the value and significance of the product, and then carry out quantitative restriction sales in the later stage to achieve a premium goal. 
In this way, cross-border cooperation often creates a sense of scarcity for people, so the non-product functions of cooperative models emerge at times. For example, people will collect these products, auction them, or buy them back as gifts.

\subsection{Problems}

Because brand collaboration models have a limited sale nature, brands cannot directly use cooperative sales as a single product line to increase store sales. This has led to a potential crisis in which brands can only become popular for a while, rather than basing on a large number of customers for long. And when the awareness of cooperation is weak and the brand awareness is not high, the sparks between these two brands often do not attract the interest of the customers and the response is flat, the cooperation like this will also consume the energy and capital of the brand investment.

Because cross-border cooperation can't make a large amount of sales for a long time, it can't firmly occupy the customer's purchasing psychology, that is, the customer flow that the brand gets during this period and the fixed customer group formed will have the potential crisis of loss in the later stage. In addition, the cooperation between some brands often lacks sincerity. Just meaninglessly stacking the brand's logos together without any sense of design, will accelerate the loss of customers.

\subsection{Customer Flow and Brand Image}

Liu Fangzhou and others analyzed the role of cross-border marketing in shaping the brand image in 2018. They proposed that cooperating with other brands for crossborder marketing has a direct impact on the brand image, which indirectly affects customer loyalty and mobility[4]. The process of choosing cooperation is quite conscious of the process of approaching consumer needs and solving consumer problems. Choosing a brand that is far from its own positioning can make consumers have a novelty[4]. It can attract consumers' attention in a short time, but in the long run, it has a very limited effect on improving the brand image[4]. Therefore, in the process of cooperative marketing, brands should maintain their own brand cultural spirit and image and continuously optimize it[4].

Because brands can help each other when conducting crossborder cooperation, the brand can transfer the customer and brand connotations accumulated in the market by the other side conveniently, thereby increasing its popularity and brand influence. At the same time, different brands correspond to different fixed consumer groups, which are the so-called loyal customers. The convenience of cooperation can enjoy two sets of loyal customers at the same time, because they have similar consumption habits and aesthetic preferences, which not only ensures consistent marketing goals but also expands the consumer market. Because the brand is an intangible asset with economic value, in the long run, the spirit of the two brands will affect each other and affect the customer's awareness, so that customer loyalty will continue to flow in these two brands.

\section{CONCLUSION}

Through the research and study of reports published by StockX and various articles from peers, the author can conclude that cross-border cooperation between brands can indeed improve brand marketing, and at the same time can optimize the brand culture to a certain extent and maintain the brand image The establishment of the brand to enhance the market weight of the brand and the consumer awareness of the brand. Moreover, cross-border cooperation between different brands (brands and celebrities, brands and IPs, brands and brands) is also conducive to enjoying different and diverse resources at the same time, which can achieve the purpose of attracting fans to each other. This will undoubtedly maintain consumer loyalty to the brand, and will add up and share the different customer loyalty enjoyed by the two cooperating brands.

Not all brand cooperation can sell well. Brands must also see that there are many cross-border collaborations that are not well-known and do not attract consumers. These collaborations have no topics and no fans. So here are some suggestions for the brands` and partners reference. Brands should wait for fans to have enough enthusiasm and user loyalty for cooperation topics before release, otherwise they will not achieve the effect of $1+1>2$, and will simply consume funds and experience, making their business path narrower. Before the brand is sold, there should be enough suspense to make the topic hot, and use various aspects of publicity to form a comprehensive and deep interaction between the brand and the fans and consumers, which can better promote the sales and communication of the product. Brands should first conduct in-depth surveys of the consumer groups 'lifestyles, aesthetic preferences, and spending power, and integrate these factors to specify targeted sales strategies and limit sales to enhance customers' desire to buy. Brands should seize the opportunity of cross-border cooperation to integrate resources, carry out the double superposition of consumers and brand value, in order to promote the brand and improve the brand to cover the crowd. At the same time, create its own cultural symbol, that is, to establish the correct brand image in the consumer group. This can provide a good cultural output for user awareness and living habits, and strengthen user loyalty to the brand.

The article has some limitations in the study due to time constraints. The author cannot analyze in detail the crossborder cooperation of all brands in the market, so there just displays the phenomena and trends in the market, so as to provide suggestions and summarize the theory. At the same time, due to the unavailability of some information, for example, in this article, annual reports of some companies are not included, etc. Besides, the authority of the data can be improved. In the future study in this area, the author will do more detailed research and verify the result again. 


\section{ACKNOWLEDGMENT}

First and foremost, I would like to show my deepest gratitude to my teachers and professors in my university, who have provided me with valuable guidance in every stage of the writing of this thesis. Further, I would like to thank all my friends and roommates for their encouragement and support. Without all their enlightening instruction and impressive kindness, I could not have completed my thesis.

\section{REFERENCES}

[1] Y. Bai, F. Wang. Analysis of Clothing Brand Joint
Marketing. Journal of Clothing Research, 2019, 4(4), pp.367-371.

[2] H. Wu. Clothing Brand Marketing Strategy. Shanghai: Donghua University Press. 2016

[3] N. Xu, P. Zhu. The Application of Cross-border Marketing in Brand Communication. Chinese Market, 2013(25), pp.11-14.

[4] F. Liu, Q. Xia. Analysis of the Role of Cross-border Marketing in Shaping the Brand Image. Journal of News Research, 2018, 9(7), pp.72-73.

[5] StockX News. 2020. StockX Snapshot: The State of Resale. Accessed on 16 February 2020. https://stockx.com/news/state-of-resale/. 